\title{
The Guiding of Marxism Popularization to the Ideological Guidance Work of Youth
}

\author{
Ying Huang ${ }^{1 *}$ \\ ${ }^{1}$ School of Chinese language and literature, Zhaoqing University, Zhaoqing, Guangdong 526061, China \\ *Corresponding author. Email: $908841744 @ q q . c o m$
}

\begin{abstract}
The popularization of marxism is in common with the ideological guidance of youth. On the basis of the logic relation between sorting out, find the current main problems of youth ideological and leading the work, and then analysis the popularization of marxism youth ideological and lead the work in a firm ideal faith, improve the team construction, strengthen the consciousness of innovation, pay attention to personal development provide guidance on the four dimensions, and condensed firm faith to education, the task with high quality and explorations in a new era of successor.
\end{abstract}

Keywords: popularization of marxism, the youth, thoughts lead

\section{马克思主义大众化对青年思想引领工作的指导向度}

\author{
黄颖 $1^{*}$
}

1 肇庆学院文学院讲师, 思想政治教育研究方向, 526061, 908841744@qq.com。

\section{摘要}

马克思主义大众化与青年思想引领工作具有相通性。在理清两者逻辑关系的基础上, 找到当前青年思 想引领工作存在的主要问题, 进而分析马克思主义大众化为青年思想引领工作在坚定理想信念、完善 队伍建设、增强创新意识、注重个人发展四个维度上提供的指导，对培养和凝聚信念坚定、素质过硬、 勇担重任的新时代接班人大有裨益。

关键词：马克思主义大众化；青年；思想引领

\section{1.前言}

在党的十九大报告中, 习近平总书记作出了“中国特 色社会主义进入新时代”的重大政治论断, 提出“培养担当 民族复兴大任的时代新人”[1]。一代人有一代人的使命, 一代人有一代人的担当。青年一代有理想、有本领、有 担当, 国家的未来就有发展, 民族的未来就有希望。因 此, 在新时代做好青年思想引领工作, 是事关国家发展、 民族振兴与社会进步的重要命题。

基于对青年思想引领工作重要性的认识, 党和国家 对科学引导青年用马克思主义的理论和实践成果充实自 身进行了积极实践。但在新的历史起点上如何结合时代 特色和青年特点将马克思主义融入青年生活, 由意识形 态转化为文化心理结构, 成为青年的价值基础和精神纽 带，是十分值得思考的问题。

\section{2.马克思主义大众化与青年思想引领工作的逻 辑关系}

马克思主义大众化与青年思想引领工作是相辅相成 的。一方面, 马克思主义大众化是一个从意识形态到文 化心理结构的渐进过程, 这个渐进过程的发展需要有马 克思主义理论研究者与实践者的推动。而做好青年思想 引领工作能吸引一批有理想有信念的青年马克思主义者 加入到马克思主义理论研究与实践的队伍中, 为马克思 主义大众化的实现提供不竭动力。另一方面, 马克思主 义思想具有丰富的内涵实质, 马克思主义大众化的过程 更是会产生大量的具有时代意义的理论成果, 积极吸收 马克思主义大众化的理论成果, 能帮助青年思想引领工 作理清时代内涵和工作重点，进一步增强工作的亲和力、 针对性和实效性，从而实现青年思想引领工作的新突破。 


\section{3.当前青年思想引领工作存在的主要问题}

\section{1.思想认识上, 未能深刻认识理想信念的作用}

当前我国意识形态领域存在新自由主义、西方宪政 民主、西方新闻观、公民社会、历史虚无主义、普世价 值等错误思潮。在信息化高度发达的时代, 各种社会思 潮通过各种现代媒介迅速传播, 交互影响、相互渗透。 错误思潮在信息化的时代的传播也变得更为隐秘、迅速, 对青年理想信念产生极大的冲击。但少数高校在开展青 年思想引领工作的过程中, 还未能深刻认识到这些错误 思潮的危害, 对理想信念重要性的认识浮于表面, 在青 年理想信念的宣传引领工作精力、资源投入不足, 导致 部分青年观念偏离正轨: 重视自身利益多于群体利益, 重视专业技能多于理想信念, 重视眼前利益多于长远发 展。

\section{2.工作格局上，未能真正确立“以生为本”理念}

青年思想引领工作的主体是青年，这就决定了在开 展工作的格局上必须确立“以生为本”理念。“以生为本” 理念, 要求高校在青年思想引领工作中更突出“人文关怀”, 把学生当作有思想、有感情、有权利的主导者来看待, 而不是实现政绩或完成工作的工具。但少数高校在开展 青年思想引领工作时, 不是从青年的自身成长出发, 而 是将青年视为完成上级布置任务、开展形象工程的工具。 “用宣传到位代替工作到位”“不怕学生不满意, 就怕领导 不注意”, 严重偏离了“以生为本”的理念, 对青年的主观 能动性和主体地位未能给予足够重视。

\section{3.工作方式上，仍存在形式主义、官僚主义倾 向}

目前少数高校在开展青年思想引领工作的过程中, 未能有效结合大学生的特点和时代需求来开展精准服务, 更多的是以传统简单、快速粗暴的“行政命令”去管理学生, 官僚主义倾向严重, 不能真正赢得广大青年学生的认同 和尊重, 开展工作的基础被严重削弱。一是部分高校在 组织各种活动时, 更多的把重心放在组织形式上, 过于 讲究留痕, 或者为了宣传照片和视频的美观, 以任务的 形式出现, 硬性摊派参加人数, 并不注重提升活动本身 质量来提高对青年的吸引力。二是把青年思想引领的活 动与个人的功利挂钩, 参加活动的学生能加综合测评分, 综合测评分数高低直接与评奖评优挂钩。造成部分学生 参加活动只看有没有综合测评分加, 或是为了评奖评优 四处参加活动凑人头。三是在活动中, 没有主动积极组 织更多的青年参与, 做到思想引领全面覆盖, 而是为了 活动展示效果, 安排熟悉的服从性高的学生干部参与,

\section{4.工作方法上, 缺乏锐意创新的勇气}

当前仍有部分高校在开展青年思想引领工作时, 存 在照搬照抄和不求有功但求无过的工作思维, 工作方法 年年一样, 没有适应时代变化根据新青年、新媒体的特 点来开展工作。更有甚者把思想引领工作片面地理解为 讲座宣传和开会布置, 认为开了会发了文工作就是完成 了, 缺乏足够勇气和魄力去改革创新。活动方法手段、 理论育人方式、服务保障机制年年一样, 或是换汤不换 药, 未能真正满足学生需求, 工作的吸引力、感染力不 足, 导致部分青年出现表面接受内心排斥的现象。

\section{4.马克思主义大众化指导青年思想引领工作的 四个维度}

\section{1. 为坚定理想信念提供理论指导}

坚定理想信念是青年思想引领工作的核心灵魂。开 展青年思想引领工作就是对青年进行马克思主义理论、 中国特色社会主义理论、共产主义理想信念等思想政治 教育。而推进马克思主义大众化, 对马克思主义理论内 容进行艺术化、形象化、生动化、趣味化加工, 可以为 青年思想引领工作提供更为容易理解、容易接受的理论, 使青年在思政素养和理论水平上得到长足的提高。纵观 新中国成立以来的发展历程, 可以发现, 任何青年思想 引领工作的举措, 都是建立在马克思主义这一根本指导 思想上的。一方面, 在开展思想引领工作时, 要筑牢马 克思主义的坚实指导地位。坚定的理想信念, 必须建立 在对马克思主义的深刻理解之上, 建立在对历史规律的 深刻把握之上[2]。另一方面, 在开展思想引领工作时, 要积极实现马克思主义大众化, 不断为马克思主义的实 践增加时代色彩和地域色彩。让广大青年随着马克思主 义大众化的纵深推进, 积极主动地去学习、实践马克思 主义，树立保持坚定的理想信念。

\section{2. 为完善队伍建设提供方法指导}

完善队伍建设是青年思想引领工作的重要保障。毛 泽东早在 1938 年就在《新阶段论》中提出, 如果我们党 有一百个至两百个系统地而不是零碎地、实际地而不是 空洞地学会了马克思列宁主义的同志, 就会大大提高我 们党的战斗力, 并加速我们战胜日本帝国主义的工作 [3]。 但在高校里, 青年思想引领工作大多由辅导员和共青团 干部负责, 不仅对专业性要求较高, 而且工作没有时空 观念、身心压力极大, 这给从事青年思想引领的工作者 
既要让青年明白肩负的责任也要解决好青年的个人发展 问题。因此, 青年思想引领工作要做好以下几点: 第一, 理论教育必须讲深讲透, 真正做到理论联系实际, 能够 自如运用用马克思主义理论分析、解决问题, 解答不同 青年对政治理论和认识的疑虑和困惑。第二，在思想引 领过程中, 要结合青年自身个性倾向、心理特征、自我 意识等特点, 锻炼青年独立思考、解决问题的能力, 以 便不同的青年根据自身的特点调整节奏，推动个人发展。 第三, 引导青年自觉进行自我管理、促进自我发展。时 代不断变化, 社会也在不断进步, 人才标准也在不断提 高, 青年要紧跟社会节奏, 适应社会需求。

\section{REFERENCES}

[1] Xi Jinping,Report to the 19th national congress of the communist party of China,The People's Daily,2017-10-19 (01)

[2] Selected and edited important documents since the 18th CPC national congress (part ii),Beijing: central document publishing house, 2018, pp. 348

[3] Selected works of MAO zedong (volume ii),Beijing: people's publishing house, 1991, pp. 533

[4] The introduction to the basic principles of marxism,Beijing: higher education press, 2010, pp. 42

[5] The complete works of Marx and Engels: volume 27,Beijing: people's publishing house, 1972, pp. 433

\section{4. 为注重个人发展提供认识指导}

注重个人发展是青年思想引领工作的牢固根基。这 与经典马克思主义思想“正确的理论必须结合具体情况并 根据现存条件加以阐明和发挥 [5]”是不谋而合的。青年思 想引领工作是一种国家、民族层面的方向原则性教育, 同时也要结合具体情况关注不同青年个人成长的现实问 题。青年在求学期间不可避免会出现学业困难、交际冲 突、情感困惑、就业创业困难、心理障碍等一些现实性 问题, 这些问题各不相同, 但都具有现实性, 是青年成 长成才过程中不可回避的。要做好青年思想引领工作, 必须要兼顾对青年的方向原则性引导和个人发展相结合, 